\title{
Effectiveness of the Primextra Gold in controlling weeds of Cucumber (Cucumis Sativus
} L.)

\author{
*UGWUNNA R.U ${ }^{1}$, *OCHEKWU, EB ${ }^{2}$. *ANYANWU, DI ${ }^{3}$. \\ Department of Plant Science and Biotechnology, Faculty of Science, University of Port Harcourt.
}

\begin{abstract}
The efficacy of Primextra Gold herbicide in controlling weeds in cucumber was evaluated in this research. The experiment was laid out in a randomized complete block design with four replications. Seven weed control treatments - 0.0, 0.25, 0.5, 0.75, 1.0, 1.25 and $1.5 \mathrm{~kg}$ a.i/pot - were applied pre-emergent for this study. The dry weight, height of plant, number of green leaves, weed control efficiency, weed persistence index, crop phytotoxicity rating, weed destruction rating, weed count (total number of weeds), weed flora and classification were used to determine the herbicide efficacy and crop safety. Results show that the effects of the treatments were mostly significant; all the treatments caused over 50\% injury to the cucumber at all stages except at 7 Days After Treatment. At the end of the experiment, results show that the treatments were highly toxic as they caused up to $100 \%$ injury to the cucumber preventing height, dry weight or leaf number measurements to be taken except in pots which received $0.25 \mathrm{~kg}$ a.i $/$ pot of the herbicide and the control. Weed destruction ratings was over $50 \%$ for all of the treatments and at all stages, except for $0.25 \mathrm{~kg}$ a.i/pot at 21 and 28 DAT. Weed density and dry weight were significantly reduced by the treatments. WCE\% recorded was over 50\% while WPI was zero (0) for all treatments except $0.25 \mathrm{~kg}$ a.i $/$ pot. Common weeds observed include Oldelandria corymbosa and Digitario sp.

(C) JASEM
\end{abstract}

http://dx.doi.org/10.4314/jasem.v19i4.1

KEY WORDS: Weed control efficiency, weed persistence index, crop phytotoxicity rating, weed destruction rating and weed count.

\section{INTRODUCTION}

Herbicides are widely used for control of weeds in both agricultural and non-agricultural situations because they provide effective control of weeds (Altland, 2003). With the increasing array of products and the continuing refinement of application equipment, herbicides are effective and practical in a wide variety of weed control situations. (Ashley, et al., 2008). Most herbicides are initially discovered, developed and registered for use in major crops such as corn, soybeans, grains, cottons and sugar beets. Very little, if any crop screening efforts are directed toward minor crop that include high value vegetable crops. There is a limited availability of herbicides for some curcubits (Tickes, 2012; Sosnoskie, et. al., 2013). MacLeod (2001) also reported that as at 1997, only one herbicide was registered for use in cucurbits which controlled only grasses and due to the absence of registered herbicides, "weeds are probably the most important cause of cucurbit yield loss". According to Shiboleth, et al. (2001), in the past decade, no new herbicides have been labelled and none are known to be under development for cucurbits. Gianessi and Williams (2011) identified the need for subject matter specialists capable of evaluating weed problems and formulating herbicide recommendations on a per country basis.
Primextra Gold which is a recently introduced herbicide in Nigeria has not been widely applied by farmers. It is used to control annual grasses and broad leaf weeds in maize, sugar cane, sweet corn and oxabetrinil (Concep safener) treated sorghum.

Therefore, in order to expand the range of herbicides available for use in cucumber and provide a potential alternative herbicide, the objective of this study is to analyse the effectiveness of the pre-emergent herbicide, Primextra Gold in controlling weeds of cucumber and to determine its safety for use in cucumber.

\section{MATERIALS AND METHODS}

The field experiment was conducted between February and March, 2013 in the botanical garden of the University of Port Harcourt, Rivers state, Nigeria. The experiment was laid out in a randomized complete block design with four replications (Table $1)$.

Six (6) seeds of cucumber were planted in each container. Cucumber seeds (Cucumis sativus), obtained from the local market were used for the experiment. Primextra Gold was applied postplant preemergence with $\mathrm{CO}_{2}$ pressurized backpack sprayer. Sufficient quantity of moisture was maintained in the soil at the time of application. 
Table 1: Treatments applied

\begin{tabular}{ll}
\hline Treatments & Primextra Gold Concentration \\
\hline T1 & Control $-0.0 \mathrm{~kg} \mathrm{a.i} /$ pot \\
T2 & $0.25 \mathrm{~kg} \mathrm{a.i} / \mathrm{pot}$ \\
T3 & $0.5 \mathrm{~kg} \mathrm{a.i} / \mathrm{pot}$ \\
T4 & $0.75 \mathrm{~kg} \mathrm{a} . \mathrm{i} / \mathrm{pot}$ \\
T5 & $1.0 \mathrm{~kg} \mathrm{a.} / \mathrm{pot}$ \\
T6 & $1.25 \mathrm{~kg} \mathrm{a} . \mathrm{i} / \mathrm{pot}$ \\
T7 & $1.5 \mathrm{~kg} \mathrm{a.i} / \mathrm{pot}$ \\
\hline
\end{tabular}

Weed Data Collection: Following are the observations recorded and the techniques followed.

Weed count: The total number of weeds present was recorded at 14 DAT and 28 DAT by identifying and counting the weeds present in each of the pots. The density was expressed as number of weeds per pot and subjected to statistical analysis. The various weed species were categorized as either broadleaf, grasses or sedges.

Dry weight of weeds: Cucumber shoots were cut at 28 DAT at the soil surface and the collected samples were oven-dried at $70^{\circ} \mathrm{C}$ to a constant weight, weighed and results recorded. Dry weight of weeds per pot was worked out and expressed in $\mathrm{g}$ per pot and subjected to statistical analysis.

Weed Control Efficiency (WCE \%): It expresses the percentage $(\%)$ reduction in weed population due to weed management practices over control. The weed control efficiency was calculated as follows:

Weed Persistence Index (WPI): Is used to indicate the resistance of weeds against various tested treatments and to confirm the effectiveness or the herbicidal efficiency of the selected treatments to kill the weeds (Denasenapathy, et al., 2008). It was calculated using the weed count and the dry weight of the weeds.

Weed destruction rating: Visual ratings of weed destruction were taken $7,14,21$ and 28 DAT to determine the extent of destruction caused by the herbicide treatments on weed using a scale of $0-$ 100.

Cucumber Data Collection: Growth components: For recording, the various growth components were taken at 7, 14, 21 and 28 DAT. Plant dry weight, height, leaf number were used as quantitative measure representative of plant vigour.

Plant height $(\mathrm{cm})$ : The plant height was measured from the base of the plant (at soil surface) to the tip of the main shoot of the plants and mean of plant height was worked out and expressed in centimeters per pot.

Number of green leaves per plant: The numbers of leaves were obtained by physical count of the leaves in the pots and average number of leaves per pot was worked out.
Dry matter accumulation: Samples were taken at 28 DAT. Their shoots were cut at the soil surface and the collected samples were oven-dried at $70^{\circ} \mathrm{C}$ to a constant weight, weighed and results recorded.

Crop phytotoxicity: Visual ratings of crop toxicity were taken 7, 14, 21 and 28 Days-After-Treatment (DAT) to know the extent of toxicity caused by the herbicide treatments on cucumber using a scale of $0-$ 100.

Statistical Analysis: The data collected for each were subjected to analysis of variance (ANOVA). The level of significance used in ' $F$ ' and ' $t$ ' test was $\mathrm{P}=0.05$.

\section{RESULTS AND DISCUSSIONS}

Weed Destruction Rating: Results show that at all stages, over $50 \%$ weed destruction was observed where $0.5-1.5 \mathrm{~kg}$ a.i $/$ pot treatment was applied while $0.25 \mathrm{~kg}$ a.i $/$ pot only caused over $50 \%$ weed destruction at 7 and 14 DAT. Weed destruction increased with increased treatments but with time, the weed destruction reduced and this may be attributed to the wearing off of the effect of the herbicide and emergence of new weeds overtime.

Crop Injury: Herbicides are expected to kill weeds and protect crops from weed competition without harming the crops. Cucurbits are generally more susceptible to injury from most herbicide applications, including registered herbicides and managing the diversity of broadleaf weeds and sedges in cucumber, squash and pumpkin fields is difficult.

The herbicide treatments caused more damaging effect. At 7 DAT, treatments $0.25-1.25 \mathrm{~kg}$ a.i $/$ pot had slight effect on the cucumber while treatment $1.5 \mathrm{~kg}$ a.i $/$ pot had moderate effect on the cucumber. The slight effect indicated a non-lasting more pronounced crop injury while the crop usually recovers from the moderate injury. At 14 DAT, cucumber plants suffered over 50\% crop injury for all treatments even recording $100 \%$ crop injury for treatments $0.75-1.5 \mathrm{~kg}$ a.i $/$ pot. At 21 and $28 \mathrm{DAT}$, all cucumber crops suffered $100 \%$ injury except for cucumber treated with $0.25 \mathrm{~kg}$ a.i $/$ pot. Studies have also shown that severe injury and/or stand reduction 
often occurs when dinitroaniline herbicides are applied PRE to seeded cucurbit crops because of root and shoot damage (Grey, et al., 2000). Cucumber (cv. Qi Feng) has also been shown to be very sensitive to the application of Acetachlor and Stomp even at a concentration of $5 \mathrm{mg} / \mathrm{kg}$ (Song, et al., 2006)

Effect of herbicide treatments on total number of weeds (Fig. 1): Pots treated with $0.75 \mathrm{~kg}$ a.i $/$ pot $1.5 \mathrm{~kg}$ a.i./pot of Primextra Gold showed relatively low number of weeds indicating that application of this herbicide at these concentrations can efficiently control the total number of weeds including broadleaf, grasses and sedges. The untreated pots showed significantly higher number of weeds than the treated pots (Fadayomi et al., 1984; Babu, 2008; Singh et al., 2013). The number of weeds found decreased with increased herbicide treatments showing the efficiency of increased treatment of the herbicide in reducing weed density. This result is in agreement with Hafeezullah (2000), Sobotka and Barlow (1983) and Khan et al., (2003) who reported that weed control methods significantly affects weed density $\mathrm{m}^{-2}$.

Effect of herbicide treatments on dry weight of weeds (Fig..2): The total dry weight of weeds as influenced by different Primextra Gold treatment at the different stages of the cucumber indicated significant differences. Treatment 0.5 to $1.5 \mathrm{~kg}$ a.i $/$ pot caused the least dry weight of weeds - zero (0). This low dry weight observed in the treated pots may be ascribed to lesser number of weeds, rapid depletion of carbohydrate reserves of weeds through rapid respiration (Babu, 2008). Mutnal (2006) also reported that reduced dry weight of weeds are mainly due to the lower weed population per unit area and suppression of weed growth as a result of effective control of weeds by the herbicides.

Effect of Primextra Gold on dry weight of cucumber (Fig. .3): The cucumber dry weight was significantly affected by the herbicide treatments. The dry weight of the cucumber was only recorded in the control and cucumber treated with $0.25 \mathrm{~kg}$ a.i $/$ pot. The dry weight of cucumber treated with $0.5-1.5 \mathrm{~kg}$ a.i./pot was zero (0) and that of the control and cucumber treated with $0.25 \mathrm{~kg}$ a.i./pot recorded $0.88 \mathrm{~kg}$ and $0.44 \mathrm{~kg}$ respectively. Based on the results obtained from the dry matter of cucumber, it can be said that, the Primextra Gold concentrations used was highly injurious to the cucumber making it unsuitable for application in the control of weeds of cucumber. This lower dry matter accumulation may be as a result of reduced number of stands or stand loss which can be attributed to toxic concentrations of Primextra Gold. Heuer, et al., (1991) also reported that the fresh weights of cucumber leaf and root were severely inhibited when treated with $1.75 \times 10-7 \mathrm{M}$ Metolachlor although almost full recovery was observed 3 weeks later.

Weed flora: Ten different weeds were found in the untreated pots and this number reduced significantly on application of the herbicide. The most common weeds found were Oldelandria corymbosa, Sedges and Digitario sp. as they occurred in the treated pots and in virtually all treated pots. There were fewer weeds at 14 DAT compared to the number of weeds at 28 DAT indicating that the effect of the herbicide wore off overtime and that there was new weed growth. New weeds were observed in all the pots by 28 DAT and the untreated pots had a relatively high density and population of weeds which reduced significantly with the increased herbicide concentration. There were more broadleaf weed species than grass weeds and sedges. Khan, et al. (2013), have also reported best control of broadleaf and grass weeds in maize by Primextra Gold.

Effect of herbicide treatments on the height of the cucumber (Fig1.4): Cucumber height was significantly affected by all the treatments especially treatments $0.5 \mathrm{~kg}$ a.i $/$ pot $-1.5 \mathrm{~kg}$ a.i $/$ pot which reduced cucumber height to zero (0) while treatment $0.25 \mathrm{~kg}$ a.i/pot reduced cucumber height from $25 \mathrm{~cm} /$ pot at 14 DAT to $21 \mathrm{~cm} /$ pot at $28 \mathrm{DAT}$. At $7 \mathrm{DAT}$, the highest average cucumber height was recorded in pots treated with $0.5 \mathrm{~kg}$ a.i $/$ pot while at $14 \mathrm{DAT}$, the highest cucumber average height was recorded in the control followed by plants treated with $0.25 \mathrm{~kg}$ a.i $/$ pot of the herbicide. By 21 and 28 DAT, the cucumber height was only recorded in the control and cucumber treated with $0.25 \mathrm{~kg}$ a.i $/$ pot while those treated with higher concentrations $(>0.25 \mathrm{~kg}$ a.i/pot $)$ were destroyed. This reduction in average height in all pots may be as a direct result of stand loss / reduced number of cucumber stands available for measurement.

Effect of the herbicide treatments on the number of cucumber leaves (Fig. 5): The effect of the herbicide treatments on the average number of leaves of the cucumber was significant at all stages. At 14 DAT, the most number of leaves was recorded in the control and the least was recorded in cucumber treated with $1.5 \mathrm{~kg}$ a.i $/$ pot. Treatments of the herbicide higher than $0.75 \mathrm{~kg}$ a.i $/$ pot resulted in significantly lower average number of leaves in cucumber.

The number of leaves registered for cucumber was significantly lower in the treated pots compared to the untreated pots. By visual observation, the leaves showed discolouration and were smaller compared to leaves in the untreated pots. As observed in the height and dry weight of cucumber, at 21 and 28 DAT, there were no leaves observed in pots treated with $0.5-$ $1.5 \mathrm{~kg}$ a.i $/$ pot and this again indicates that the 
herbicide treatments were highly injurious / toxic to the cucumber.

The leaf is the basic photosynthetic machinery for plant food; hence its size or presence would directly affect the yield and yield components of a crop (Khan, et al., 2003). Jerzykiewicz and Klobus (2007) also showed that exposure of cucumber seedlings to simazine or linuron strongly decreased the photosynthetic electron transport.

Weed Control Efficiency (WCE\%) (Fig. 6): Weed Control Efficiency expresses the percentage (\%) reduction in weed population due to weed management practices over control. It is employed to determine the effectiveness of herbicides in weed management (Mutnal, 2006).

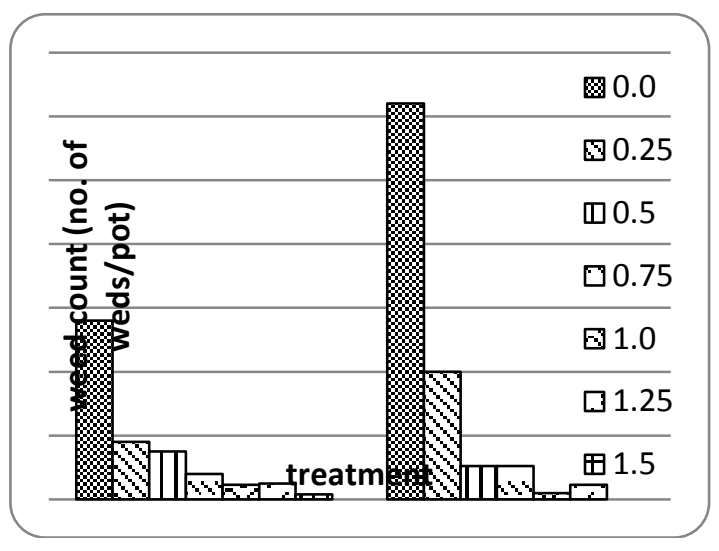

Fig. 1.: Weed count at 14 and 28 DAT

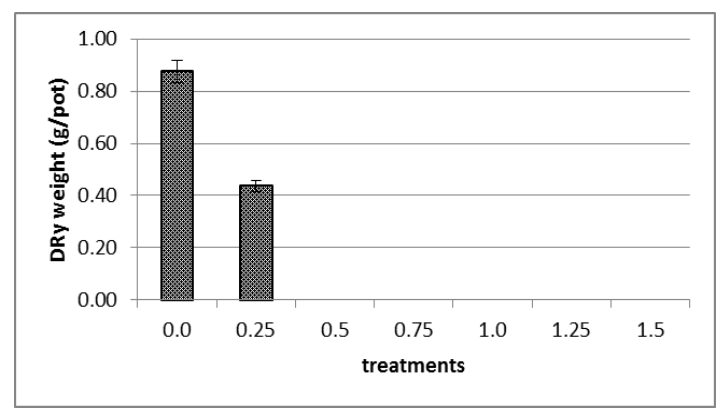

Fig..3: Effect of the herbicide treatment on cucumber dry weight at 28 DAT

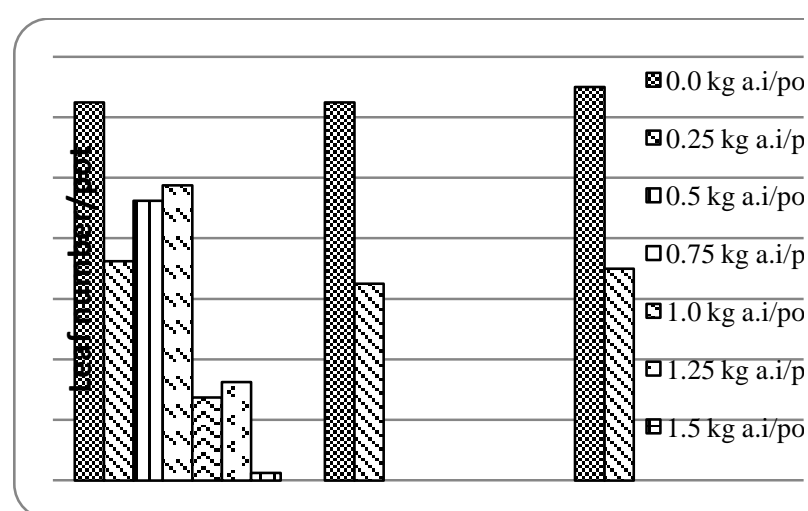

Fig 5: Effect of herbickide treatment on 1 eaf nember at different stages of growth

*UGWUNNA R. $U^{l}$., OCHEKWU, E.B ${ }^{2}$.AND ANYANWU,D.I ${ }^{3}$
WCE\% was above $50 \%$ in all treated pots and at all stages. WCE\% ranged from $84 \%-100 \%$ at 14 DAT. At 28 DAT, WCE\% was $100 \%$ in treatments 1.25 and $1.5 \mathrm{~kg}$ a.i $/$ pot. The results indicate the capacity of the herbicide concentrations to control weeds by reduction and to the point of complete weed destruction. Mutnal, 2006 also reported that the higher WCE\% in treatments was mainly due to lower total weed population.

Weed Persistence Index (WPI) (Fig. 7): The Weed Persistence Index (WPI) of the weeds in the cucumber pots was zero (0) for all treatments except those treated with $0.25 \mathrm{~kg}$ a.i $/$ pot. A lower weed persistence index value means a higher level of weed control efficacy of a given treatment and vice versa (Khaliq, et al., 2011).

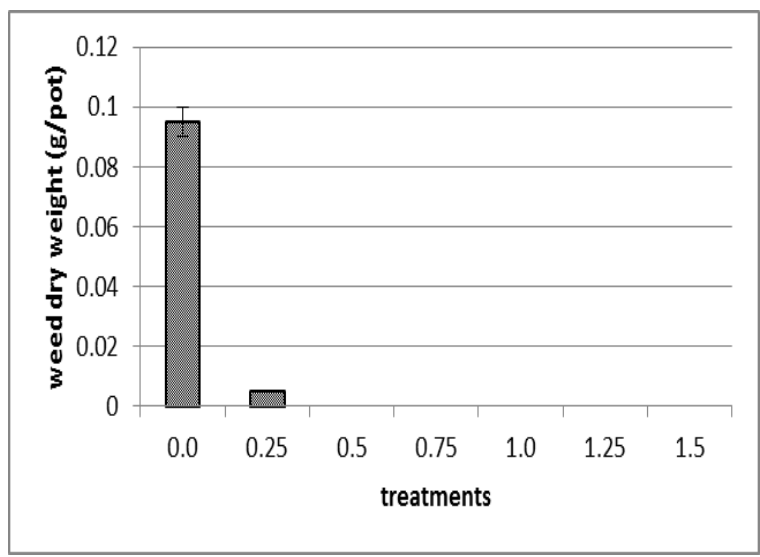

Fig. 2: Effect of the herbicide on the weed dry weight

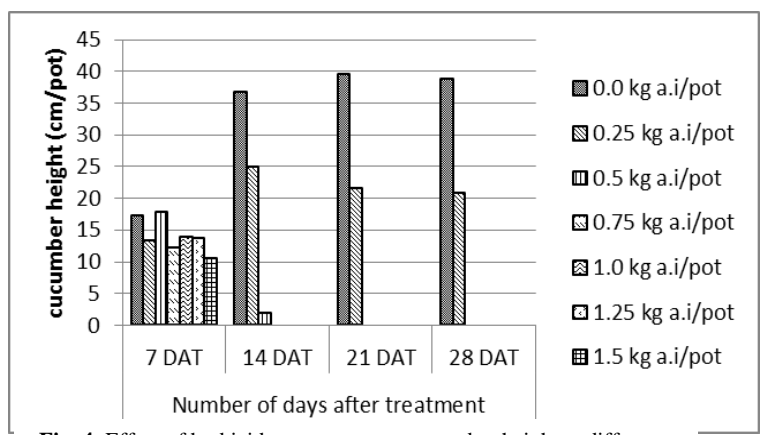

Fig. 4: Effect of herbicide treatments on cucumber height at different stages of growth

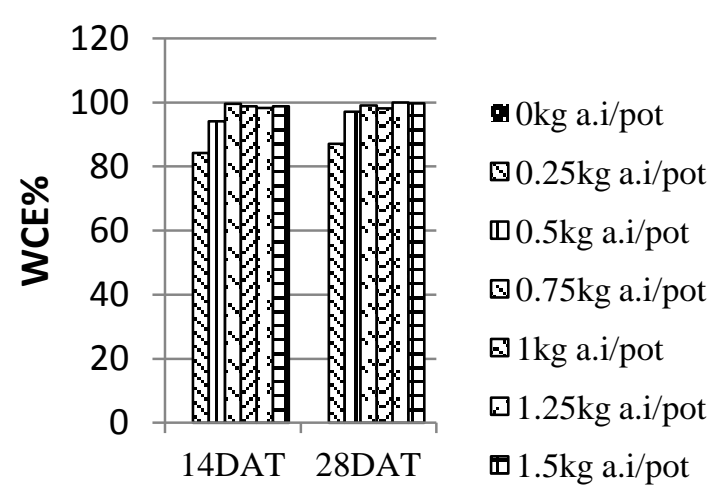

Number of days after treatment

Fig..6: Weed Control Efficiency (WCE\%) of Primextra Gold 


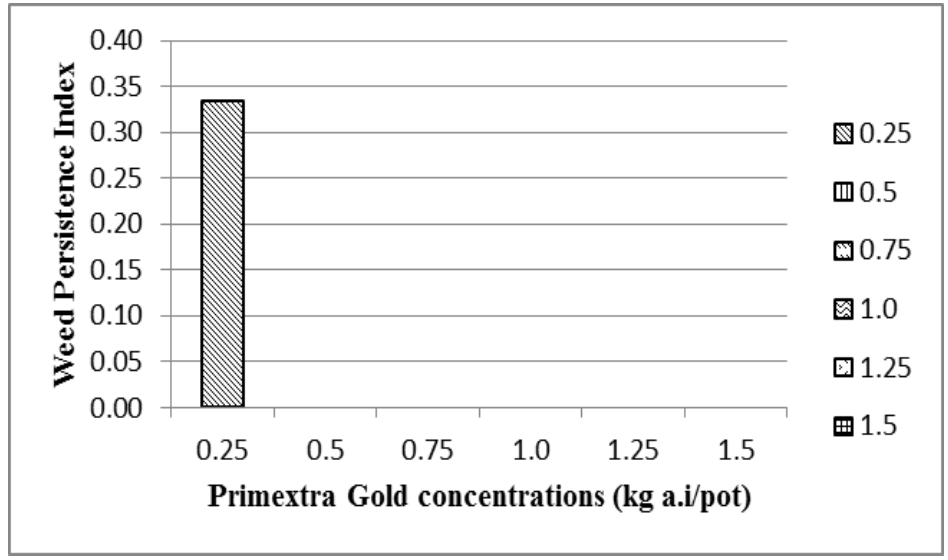

Fig..7: Weed Persistence Index (WPI)

Conclusion; This study was carried out to determine the efficacy of Primextra Gold in controlling or eliminating weeds in cucumber (Cucumis sativus) and to determine if it is safe for use in cucumber. The experiment was laid out in a randomized completely design with four replications and varied treatments of 0.0 (Control), $0.25,0.5,0.75,1.0,1.25$ and $1.5 \mathrm{~kg}$ a.i /pot of Primextra Gold and the results obtained are summarized below.

The total number of weeds, dry weight of weeds reduced with increased herbicide concentration and was significantly higher in untreated pots than in treated pots.

The density and diversity of the weed flora was higher in the untreated pots than in treated pots. There were more broadleaf weeds than grass weeds and sedges.

The low Weed Persistence Index (WPI) recorded confirmed the effectiveness of Primextra Gold in controlling / reducing weeds population.

Primextra Gold has a high Weed Control Efficiency (WCE \%)

Cucumber suffered a $100 \%$ crop injury from some treatments

While the herbicide was able kill or control weeds up to $100 \%$ which was commendable, its effect on the cucumber observed through such parameters as height, number of leaves, dry weight, crop injury etc.; and compared to untreated pots; showed high phytotoxicity to the cucumber. The injury cucumber may be attributed to aspects of the environment, season, the plants vulnerability to Primextra Gold, etc. Considering that the reason for the use of the herbicide is not only to reduce weed significantly, but also to increase crop yield or maintain a particular level of output, the results obtained from this experiments has shown that despite the effectiveness of Primextra Gold as a herbicide for controlling weeds and also increasing the yields of some other crops such as maize, wheat etc., it should not be used, at the current concentrations for controlling weeds in cucumber as the crop suffered significant crop injury. Also, further studies are required to ascertain the response of cucumber to Primextra Gold treatments in different environments, at lower concentrations, seasons, and other conditions that may influence the herbicide effectiveness, plant's susceptibility and so on. The results further confirm the general opinion that an injury test for applicability of a herbicide has to be conducted before its application in practice.

\section{REFERENCES}

Altland, J. (2003). Weed control in container crops: A guide to effective weed management through preventive measures. Oregun State University Extension Service, 8.

Ashley, R. O., Morishita, D. W., Gardner, G. F., \& Bradish, R. (2008). Weeds. In Idaho Master Gardener Program Handbook (p. ch. 14). University of Idaho Extension.

Babu, V. (2008). Physiological studies on weed control efficiency in Turmeric (Curcuma longa L.). Dharwad: Department of Crop Physiology, College of Agriculture, Dharwad, University of Agricultural Sciences, Dharwad - 580005.

Denasenapathy, P., Ramesh, P., \& Gangwar, B. (2008). Weed Management Studies. In Efficiency of indices for agricultural management research (pp. 55 - 64). India: Sunut PAl JAin for New India Publishing Agency 2008.

Fadayomi, O., Abayomi, Y., \& El-Manhaly, M. (1984). Efficacy of selected herbicide mixtures for weed control in sugar cane. Journal of Agric. Sci., Camb, 103, 503-510.

Gianessi, L., \& Williams, A. (2011). Overlooking the obvious: The opportunity for herbicides in Africa. Outlooks on Pest Management, 211-215. 
Grey, T. L., Bridges, D. C., \& NeSmith, D. S. (2000). Tolerance of curcubits to the herbicides Clomazone, Ethalfluralin and Pendimethalin. II. Watermelon. HortScience, 35, 637-641.

Hafeezullah. (2000). Effect of different sowing and weed control methods on the performance of sunflower. M.Sc. (Hons), thesis, Agric. Univ., Peshawar, Pakistan.

Heuer, B., Brates, N., \& Saltzman, S. (1991). Growth and herbicide accumulation in cucumber exposed to residual concentrations of metolachlor in their nutrient media. J. of Environ. Sci. Health, Part B: Pesticides, food contaminant and agricultural wastes, 26(2), 209 - 217.

Jerzykiewicz, J., \& Klobus, G. (2007). The effect of Triazine- and Urea-type herbicides on photosynthetic apparatus in cucumber leaves. Acta Societatis Botanicorum Poloniae, 76(1), 4347.

Khaliq, A., Riaz, M. Y., \& Matloob, A. (2011). Bioeconomic assessment of chemical and nonchemical weed management strategies in dry seeded fine rice (Oryza sativa L.). Journal of Plant Breeding and Crop Science. Available online at

http://www.academicjournals.org/JPBCS, Vol. 3(12)(ISSN 2006-9758 ), 302-310.

Khan, M. A., Marwat, K. B., Khan, N., \& Khan, I. A. (2003). Efficacy of Different Herbicides on the Yield and Yield Components of Maize. Asian Journal of Plant Sciences, 2(3)(1682-3974 (c) 2003 Asian Network of Scientific Information), 300-304.

Khan, M. A., Marwat, K. B., Khan, N., \& Khan, I. A. (2003). Efficacy of Different Herbicides on the Yield and Yield Components of Maize. Asian Journal of Plant Sciences, 2(3)(1682-3974 (c) 2003 Asian Network of Scientific Information), 300-304.

MacLeod, I. (2001). Weed management in pumpkins and other cucurbits. Twelfth Australian Weeds
Conference. Horticultural Research \& Development Corporation.

Mutnal, S. S. (2006). Studies on efficiency of herbicides in groundnut (Arachishypogaea L.) Wheat (Triticum aestivum L.) cropping system. Thesis, University of Agriculture, Dharwad, Dharwad.

Shiboleth, Y. M., Arazi, T., Wang, Y., \& Gal-on, A. (2001). A new approach for weed control in a cucurbit field employing an attenuated potyvirusvector for herbicide resistance. Journal of Biotechnology, 37-46.

Singh, R., Singh, S., \& Gautam, U. (2013). Weed Control Efficiency of Herbicides in Irrigated Wheat (Triticum aestivum). Indian Res. J. Ext. Edu. , 13 (1).

Sobotka, F., \& Barlow, J. (1983). Banvel Herbicide: A programmed approach to economic weed control in maize. Fragmenta Herbologica Jugoslavica, 12:51-58.

Song, C., Teng, C., Tian, L., Ma, H., \& Tao, B. (2006). Seedling growth tolerance of curcubit crops to herbicides Stomp and Acetachlor. Gen. Appl. Plant Physiology, 32(3-4), 165-174.

Sosnoskie, L., Hanson, B., \& Lanini, W. T. (2013). Melon tolerance and weed control with new herbicides. California: University of California.

Tickes, B. (2012). Arizona Veg IPM: Melon weed control. Retrieved from Farm Press: http://www.westernfarmpress.com 